\title{
GERENCIANDO INTER(REL)AÇÕES HUMANAS NO PROGRAMA FÁBRICA DE CUIDADOS
}

\author{
Managing Human Interrelationships in \\ the Fábrica de Cuidados Program \\ Gerencia de Inter(rel)aciones Humanas en \\ el Programa Fábrica de Cuidados
}

Eva Maria Costa

Nébia Maria Almeida de Figueiredo

Eduardo Gusmão

Teresa Tonini

Abilio Tozini

Wilma Ferreira Araújo

\section{Resumo}

Trata da experiência de oito anos da implantação do Programa "Fábrica de Cuidados - um espaço para criar modelos e tecnologias em saúde". Questão norteadora: quanto tempo é necessário para a criação de relações seguras/sustentáveis entre docentes e comunidade e que problemas/dificuldades são vividos no cotidiano de gerenciar um programa comunitário? Objetivos: Identificar as facilidades/dificuldades destacadas nas relações entre os gestores e as comunidades, caracterizandoas; e discutir as implicações destas facilidades/dificuldades para o gerenciamento do Programa. Método qualitativo e estudo exploratório-descritivo. Os resultados indicam a necessidade de: a) conhecer e confiar no outro; b) tempo e disponibilidade; c) controle do processo. Conclusão: Necessitamos de 10 anos para fortalecer vínculos de confiança no trabalho e nas relações. Houve exigências de ceder e avançar nos desejos e nas necessidades de cada grupo, mas a experiência tem propiciado aprender buscar coletivamente outros caminhos e "fugas" para resolução de problemas da comunidade.

Palavras-chave: Inter-relação. Gerência. Organização e Administração.

\begin{abstract}
Study about the experience of eight years of the implantation of the Program "Factory of Cares - a space to create models and technologies in health". Guiding Questions: How long does it take to create secure/maintainable relationships among professors and community? What problems/difficulties are experienced in the daily management of a communitarian project? Objectives: the identifying the facilities/difficulties detached at the relationship among the managers of the Program, characterizing them; arguing the implications of these facilities/difficulties for the management. The results have pointed to the necessity of: a) know and trust on the other, b) time and availability, c) control of the process. We need of 10 years to strengthen a reliable bond to work together. This has demanded yielding and advancing into desires and of each one's necessities on the collectives issues as well as on the individual ones, but it has propitiated to learn how to search together other ways and "escapes" to solve this community problems.
\end{abstract}

Keywords:

Interrelation. Management. Organization and Administration.

\section{Resumen}

La experiencia de ocho años de la implantación del Proyecto "Fábrica de Cuidados - un espacio para crear modelos y tecnologías en salud". Tuvo como cuestión norteadota: ¿Cuánto tiempo es necesario para la creación de las relaciones seguras/sustentables entre los profesores y la comunidad? y ¿Cuáles problemas/dificultades se viven diariamente en la administración de un proyecto comunitario? Objetivos: Identificar las facilidades/dificultades separadas en las relaciones entre los encargados del proyecto caracterizándolas; discutir las implicaciones de estas facilidades/dificultades para la administración. Los resultados apuntan la necesidad de: a) conocer y confiar en el otro, b) tiempo y disponibilidad, c) control del proceso. Conclusión: necesitamos de 10 años para fortalecer un enlace de confiabilidad para trabajar juntos. Esto ha exigido momentos para ceder y avanzar en los deseos y las necesidades de cada persona en las cuestiones colectivas así como en las individuales, pero eso ha proporcionado buscas de aprendercolectivamente otros caminos y "escapes" para la resolución de problemas de la comunidad.

Palabras clave:

Interrelación. Gerencia. Organización y Administración. 


\section{INTRODUÇÃO}

\section{Uma problemática em causa}

Mesmo que um projeto tenha objeto e objetivos claramente definidos, as experiências vivenciadas em sua implantação são diversas e polissêmicas por envolver diferentes sujeitos. Conseqüentemente, teremos facilidades e dificuldades no gerenciamento de implantação porque agir envolve opiniões e olhares diferentes para uma mesma situação; envolve desejos claros e escondidos daqueles que trabalham juntos; envolve expectativas individuais e coletivas.

Tais assertivas são frutos de nossa vivência na implantação do Programa "Fábrica de Cuidados: um espaço para criar modelos e tecnologias de cuidar em saúde", na Escola de Enfermagem Alfredo Pinto (EEAP), da Universidade Federal do Estado do Rio de Janeiro (UNIRIO). Esse Programa é entendido pelos docentes como um laboratório de reflexão, ação e produção de conhecimentos sobre práticas e saberes em saúde. As pessoas da comunidade atendida o compreendem como um lugar de atender problemas presentes em suas saúdes; desvios de saúde como a diabetes e a hipertensão. Além disso, a Fábrica de Cuidados é uma oportunidade para participarem de esporte e lazer, inclusive dança de salão e balé.

A partir de nossa experiência nesse processo de implantação, é possível vislumbrar potencialidades e dificuldades não só na operacionalização, mas também, principalmente, na relação psicoafetiva entre os representantes da Universidade (EEAP/ UNIRIO) e das comunidades (ALMA e AMOVILA).

Esse vislumbre surgiu com maior ênfase quando desenvolvemos o projeto "Bairros Sul: Saúde e Ambiente nas Comunidades AMOVILA e ALMA", no Programa Fábrica de Cuidados. Nesse período, nos perguntamos: 1) Quanto tempo seria necessário para a criação de relações seguras e sustentáveis entre docentes e comunidades? 2) Que problemas e dificuldades são vividos no cotidiano de gerenciar o projeto?

Gerenciar a implantação de um Programa e seus respectivos projetos requer a aceitação da face de imprevisibilidade e de interação humana que conferem à gestão a "dimensão do ilógico, do intuitivo, do emocional e do irracional" (1:26). Por isso, queríamos pensar as relações entre os que estão dentro da Universidade (protegidos pelos rumos da violência como as das ruas) e aqueles que estão fora ou expostos às adversidades e aos perigos do mundo. Aqui se instala uma questão epistemológica, qual seja: articular espaços e sujeitos diferentes exige buscar fórmulas que criem jeitos e maneiras de se relacionar com um modo de entender saúde como empreendimento. Essa é a meta do Programa Fábrica de Cuidados em implementação.

Na verdade, o nosso problema diz respeito à ciência das relações no trabalho, na produção de conhecimento e na comunicação com o outro. Desse modo, elegemos o objeto deste estudo como gerenciamento de inter(rel)ações humanas durante a implantação de um programa comunitário.

Para dar conta às questões norteadoras e ao objeto, objetivamos: identificar as facilidades/dificuldades destacadas nas relações entre os gestores e as comunidades do Programa
Fábrica de Cuidados; caracterizar as facilidades/dificuldades como contribuição para o fortalecimento das relações entre os gestores desse Programa; e discutir as implicações destas facilidades/dificuldades para o gerenciamento do Programa.

0 estudo se justifica pelo longo tempo em que o Programa vem sendo implementado. Conforme nossas experiências, poderá contribuir para produção de conhecimentos das práticas e saberes que envolvem relações com sujeitos diversos. Em nosso caso, tem-se a universidade/comunidade como parceiros interdisciplinares, em que o saber não se sobrepõe por rígida hierarquia, mas emerge a partir das intenções e das propostas comuns.

0 registro de nossas experiências deve ampliar o olhar daqueles que se interessam por práticas coletivas e de gerenciamento. Esse registro nos estimula para busca de como nossas experiências ocorrem, em que bases se constroem e quais princípios nos norteiam.

É imprescindível assinalar que a maior justificativa deste trabalho se pauta na possibilidade de pensar e escrever sobre o ser humano como um ser possível e como elemento fundamental em qualquer processo gerencial.

Registrar experiências sobre o Programa, em uma primeira investida e fortalecida por seus 10 anos de atividades conjunta com a Comunidade, nos leva a pensar: em paradigmas/políticas para o trabalho coletivo em saúde; de que gestão/gestor estamos falando; que trabalho estamos executando; e em quais circunstâncias tomamos nossas decisões. Parece que precisamos registrar o que tem nos movido continuar e, assim, construir fundamentos diferenciados do que se estabelece, em que condições agimos e que efeitos têm surtido. Nos dois anos anteriores, nossas preocupações estavam voltadas para a construção do espaço e implantação de ações práticas no Programa.

\section{A METODOLOGIA}

Por tratar-se do registro de experiências vivenciadas no cotidiano de gerenciar um Programa comunitário, elegeu-se o método qualitativo. Há inclusão de dados quantitativos ${ }^{2}$ apenas com o intuito de fortalecer o método eleito e dar "imagem" aos dados produzidos. 0 tipo de estudo é exploratório e descritivo.

As exigências éticas em pesquisa foram cumpridas com base na Resolução n 196/96 do CNS, que regulamenta as pesquisas com seres humanos.

Após a aprovação do Comitê de Ética da UNIRIO, os dados foram coletados em documentos (atas e relatórios) dos diversos momentos em que nos reunimos como Universidade e Comunidades. Desse modo, o cenário foi o Programa Fábrica de Cuidados: um espaço para criar modelos e tecnologias de cuidar em saúde, desenvolvido na EEAP/UNIRIO.

Optamos pela análise desses documentos e pela abordagem da história sem a intenção de contar história, embora ela esteja incluída no que estamos fazendo. A história permite compreender as relações que articulam os sujeitos, grupos e organizações (sociedade). Nosso desejo foi extrair as experiências/ vivências em inúmeras e marcantes situações ocorridas durante a implementação do Programa Fábrica de Cuidados.

0 Grupo Gestor desse Programa é composto por um representante da Associação de Moradores Lauro Muller e 
Adjacências (ALMA), um da Associação de Moradores da Vila Benjamin Constant (AMOVILA), e três representantes do corpo docente e três do técnico-administrativo da UNIRIO. Esse grupo tem como função coordenar todas as atividades de saúde, esporte e lazer do referido Programa.

Os sujeitos da pesquisa foram os alunos e docentes da UNIRIO e membros das Comunidades AMOVILA e ALMA. Cabe ressaltar que todos autorizaram a identificação de seus nomes.

Em todas as reuniões, o Grupo Gestor registrou as situações e as nossas reflexões de modo pessoal e particular como nos recortes abaixo:

As associações de moradores sempre lutam por um espaço para desenvolver atividades culturais e esportivas para as suas crianças, jovens, adultos e pessoas idosas. Quando não têm um espaço, essas pessoas fazem isto[as atividades] na praça pública, 0 que é muito interessante por alguns aspectos, mas gera muita descontinuidade por conta do tempo, de não poder ter materiais, pois não tem como deixar tatames, espelhos e outros objetos mais caros, como os do kung-fu, em praça pública. Assim, esta parceria com a Escola de Enfermagem Alfredo Pinto da UNIRIO, com objetivo de cuidar de pessoas, através da mensuração de como atividades integradoras geram saúde, em seu amplo sentido, foi para nós, presidentes de associações de moradores, Deus atendendo nossas preces. Por isso, quando surgiu a ameaça de um processo judicial jogar tudo debaixo da ponte, por motivos sem a menor consistência, mas que se arrasta há vários anos, isto tem sido um grande drama. Nosso pouco tempo tem se consumido em defesa, não sabemos de que ao certo. Mas, como disse o poeta: tudo vale a pena quando a alma não é pequena. A luta continua. (Tozini)

Gerenciar um fenômeno sociológico criado intencionalmente é assim como vejo a gerência desse projeto, que reuniu três universos diametralmente opostos a princípio: Comunidade Acadêmica, Comunidade de Classe Média e Comunidade de Baixa Renda. Sobre o fenômeno sociológico criado me faltam elementos para analisá-lo à luz da sociologia, somente sou capaz de detectá-lo. No que diz respeito à Administração, éuma experiência gerencial de projeto social que somente pode ser analisado pela escola das relações humanas enquanto olhar, pois mesmo esta tem seus limites definidos pela sua dimensão na área da Psicologia, dado o alto grau de necessidade de gestão e aprendizado nas relações interpessoais destas comunidades. No nível pessoal, participar do mesmo é uma vivência que talvez seja única no Brasil, sinto-me um privilegiado, assim como todas as comunidades envolvidas. (Gusmão)

A relação inicial desta construção foi muito trabalhosa; por não ter participado desde o início da implementação do Projeto, o grupo ainda não conhecia meu envolvimento com o mesmo, a minha forma de pensar idéias e ideais. Teria que conquistar a confiança dos parceiros através do meu trabalho, para que minhas opiniões pudessem ser ouvidas; esta era uma tarefa árdua. Freqüentando as reuniões com mais assiduidade, pude começar a transpor este obstáculo e interagir melhor com os demais. Surgiram, então, os conflitos de idéias e opiniões dando lugar à angústia e à vontade de jogar tudo para o alto. A comunidade não pensava como nós, dando-me a liberdade de pensar que ela só queria um espaço para atender seus anseios quanto à prática de esporte, a saúde ficava em segundo plano. (Costa) As minhas reflexões giram em torno: 1) do empenho das professoras para a manutenção do Projeto, tendo que enfrentar várias dificuldades como: a) fazer com que a Instituição cumpra a sua parte no apoio no que diz respeito às instalações, etc; b) a falta de tempo porque elas têm que desempenhar outras atividades e c) desinteresse elou falta de estímulo de demais docentes e da própria comunidade em relação às atividades do Projeto; 2) da perseverança e entusiasmo dos Presidentes das Associações ao tentar de alguma forma ajudar aos idosos, jovens e crianças das comunidades; 3) do desinteresse dos responsáveis pelas crianças em colaborar na gerência do Programa e 4) da preocupação em perceber que a maioria dos responsáveis está interessada em manter suas crianças no Projeto apenas para que ele tenha mais uma atividade fora de casa. Concluindo: "Estamos caminhando em direção a um lugar que não sabemos quando e como chegaremos, mas vale a pena continuar caminhando". (Araújo)

Dificuldades de entendimento das propostas do Programa e de sua operacionalização. 0 Discurso construído por nós não era claro e os desejos quanto ao Programa eram diferentes. Em muitos momentos, eu tinha dúvidas das possibilidades do Programa, e em que momento poderíamos confiar mais nos outros. Nas tomadas de decisão, tínhamos o cuidado para falar do outro, embora em alguns momentos tenhamos nos desencantado. Eram muitos líderes num mesmo grupo; poderes das associações, poderes da Universidade. Nós, professores, queríamos produzir conhecimento, eles queriam que sua comunidade fosse cuidada. (Figueiredo)

Tomar decisões de forma coletiva, transparentes e claras não é uma tarefa fácil. Isso nos exige abrir mão de desejos/interesses individuais em prol da comunidade, participação efetiva nas discussões para resolução de problemas, confiar na palavra do outro e criar cumplicidade nas relações pessoais (saber que se eu "cair, alguém me levanta"). Disposição de tempo é fator complicado. Ainda mais quando se trata de reuniões noturnas e prolongadas com a comunidade ou com 0 grupo gestor. Há situações que nos levam a pensar em "jogar a toalha", em reavaliar se vale a pena tanto esforço e aborrecimento. O pior momento foi saber que havia um processo judicial contra nós sobre acusações inverídicas. Decidi continuar no e com o Programa, 
porque seria injustiça com os jovens e crianças atendidas por nós; me senti confortada e apoiada pelos demais parceiros desta estrada e pelos pais/ responsáveis das crianças do Projeto; seria estragar um sonho deles e nosso por causa de um só sujeito que nos causava danos". (Tonini).

Os destaques foram extraídos de 22 registros de reuniões ocorridas em oito anos de encontros do Grupo Gestor.

Os trechos destacados nos registros referem-se aos temas: sujeitos e ambientes. Eles apresentam questões que estavam circulantes nos corpos e nas falas das pessoas envolvidas com o Programa Fábrica de Cuidados. Conseqüentemente, "conhecer e confiar no outro"; "expectativas teóricas (dos docentes) e práticas (da comunidade) em relação ao projeto"; "tempo/disponibilidade" e "controle do processo de implantação" foram veiculados com muita freqüência nas reuniões, tornando-se dados de investigação.

\section{RESULTADOS}

\section{Produzindo Conhecimento}

É fundamental dizer que optamos por discutir os resultados em uma única categoria com a mesma denominação do título deste estudo: "Gerenciando Inter(rel)ações Humanas no Programa Fábrica de Cuidados". Para um melhor entendimento, criamos a Imagem I.

Imagem I: Sobre Gerência e Gestores

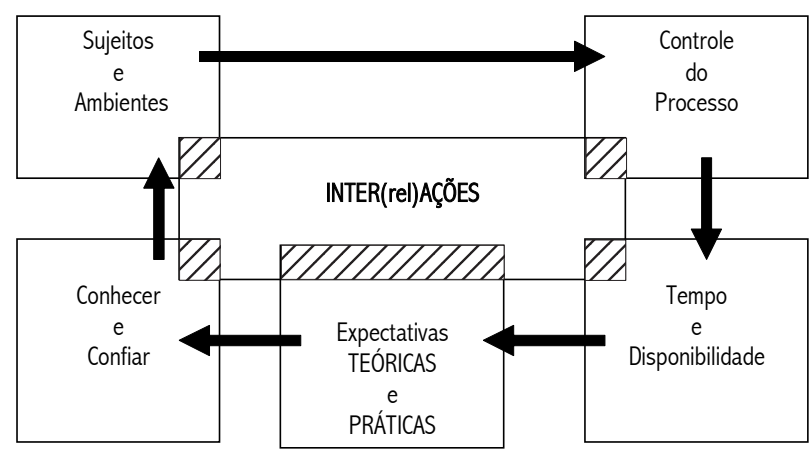

Talvez não tenhamos consciência sobre o que estamos fazendo na Fábrica de Cuidados, em especial no Projeto Bairros Sul. No entanto, é possível afirmar que criamos uma organização viva, um organismo vivo ${ }^{3}$ dentro das "células" UNIRIO e Comunidade ALMA e AMOVILA. Nesse, procuramos nos adaptar e sobreviver em um ambiente mutante por suas valiosas trocas entre as diferentes "espécies moleculares" - os moradores e os representantes das Comunidades e os professores, alunos e técnico-administrativos da Universidade.

Esse organismo vivo é estimulado e mantido pelos gestores e clientes, através de uma disciplina "camuflada" ou subjetivamente não assumida, cujo conhecimento próprio ainda não foi registrado como um conhecimento. Todavia, podemos dizer que resultados são produzidos com esforço de todos, caracterizando-se uma gestão como disciplina científica. Isto é confirmado por Nóbrega4:11 ao afirmar: "gestão é uma disciplina porque tem um conjunto de conhecimentos codificados cujo foco é a obtenção de resultados. ... Gestão é a disciplina que torna produtivos os saberes de vários campos de conhecimento, sendo por meio dela que as inovações produzem seus efeitos".

Os temas emergentes de nossas experiências apelam para várias áreas de conhecimento que compõem as inter(rel)ações humanas. Essas inter-relações são atravessadas pelos: sujeito, ambiente, conhecimento, confiança, expectativas dos sujeitos, disponibilidade de tempo e controle do processo. Isto nos obriga a pensar em nossos propósitos, objetivos e intenções, haja vista serem componentes dos resultados.

Nessa organização viva que gerenciamos não podemos desconsiderar que ao querer conhecer e confiar no outro, tivemos diferenças e interesses nem sempre apresentados no início do "namoro" - Universidade e Comunidade; professores e presidentes das associações.

Como sujeitos, estamos sempre em busca de afeto, de reconhecimento e de proteção. Ao longo do trabalho e em nós mesmos, descobrimos tais buscas, quando surgiram problemas com os instrutores e os pais, ora nos pegando de surpresa, ora denunciando nossas próprias fragilidades administrativas.

Confiar e conhecer são elementos do gerenciamento. Dizem respeito aos sujeitos envolvidos, trazendo seus poderes, saber, manias, desconfianças, medos, expectativas e interesses para o cotidiano do gerenciamento do Programa. Além disso, trazem afetos e subjetividades só identificados na expressão do corpo após algum tempo de convivência.

Para nós, gerenciar este Programa tem sido esperar e viver circunstâncias que nos colocam diante de problemas olhados e entendidos de diversas formas por cada um. Estes olhares são carregados do poder e saber que cada um acredita que tem, sem gerar efeitos que engessem o desenvolvimento do outro sujeito no Programa. 0 objetivo tem sido buscar estratégias conjuntas para nos orientar a agir-refletir-agir e a decidir como viabilizar um processo que nos mantenha vivos. Esse se tornou o maior desafio por não ser muito fácil de fazer e de se manter sustentável.

Nos apropriamos de um texto de Foster et al..$^{5}$ que trata do desafio de manter a empresa sob o enfoque do lucro e da necessidade de permanente reinvenção para que cresça de modo sustentável. Nesse sentido, foi preciso fazer uma destruição criativa nos modos de gerir as atividades da Fábrica, abrindo outros espaços e experimentando novos modelos. Assim, nos mantivemos em permanente movimento.

As expectativas acerca de nossos conhecimentos e práticas começam na forma de planejar as atividades do Programa, tanto para as ações dentro da Universidade (no espaço da Fábrica - subsolo da EEAP/UNIRI0) quanto fora dela (na Praça da Lauro Muller ou nos espaços da AMOVILA). Poderíamos dizer que somos um só corpo orgânico com três células-sujeitos; somos instituições com necessidades diversas e complexas que devem ser satisfeitas. As necessidades da Universidade têm sido a produção de conhecimento, enquanto as das Comunidades são as atividades de esporte e lazer.

A satisfação de diferentes necessidades nos direciona para abordagens gerenciais mais amplas e flexíveis, muito além das 
teorias clássicas da administração e do desempenho de metas operacionais específicas para que não se tornem fins em si mesmas. Os diferentes elementos devem trabalhar por uma interdependência funcional em que cada um age para todos os outros elementos, compartilhando funções e buscando 0 interesse coletivo para estabelecer 0 ambiente que desejam ${ }^{3}$.

Outra questão de nossa reflexão é que, algumas vezes, a teoria e a prática de gerenciamento não têm sido entendidas como um trabalho no e do ensino. Este desentendimento tem partido não só dos docentes e estudantes da Universidade, mas também dos instrutores, jovens e crianças que participam do Programa.

Mesmo sem entender claramente tal situação, nos lembramos de Taylor $^{6}$ e Fayol ${ }^{7}$, teóricos clássicos da Administração Científica do século XVIII até hoje muito utilizados na área gerencial. Muitas vezes, temos planejado as tarefas como um problema teórico. Além disso, o espírito de equipe dos gestores do Programa demonstra ter sido um processo a nos controlar e a controlar os outros - dirigir como se empregados fôssemos ou tivéssemos.

Nestes momentos, percebemos o nosso distanciamento das teorias da motivação. Nos comportamos como se não acreditássemos ser também um organismo psicológico, que luta para satisfazer as necessidades, para crescer e desenvolver$\mathrm{se}^{8}$. Surgem, então, preocupações, envolvendo desejo, política, economia, emoções e segurança como forças reais e subjetivas que nos impulsionam ora para parar, ora para prosseguir com o Programa.

A partir dessas preocupações, os estilos de pensar e de ser dos docentes de enfermagem, de engenharia, de administração e economia devem ser considerados no processo de gerir e controlar nossas ações. Eles são sujeitos que ousam afirmar que esporte e lazer também significam saúde, por isso os incluímos no Programa.

Enriquecidos pelas experiências de discutir, discordar, rir e se divertir nesse processo de gerenciar as nossas inter(rel)ações, passamos por processos positivos e negativos, porém motivadores mesmo quando pensamos em desistir. Aprendemos que gerenciar no coletivo indica que é preciso respeitar o outro e se fazer respeitar, tendo a dialógica como base desse comportamento gerencial.

Imagem II: A Biologia Gerencial

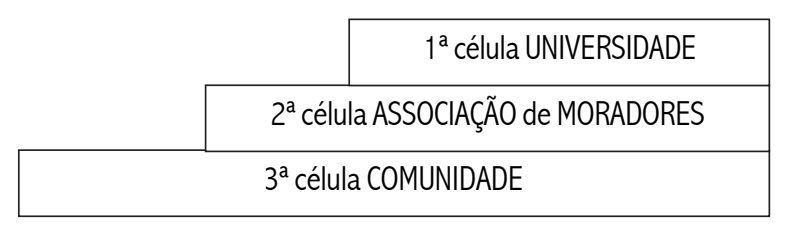

0 peso do Programa Fábrica de Cuidados é acadêmico porque nasce dentro de uma Universidade. Todavia, esse peso se perde e se desequilibra se a comunidade não tiver o seu próprio peso do outro lado da balança. Essa gerência se apresenta "biologicamente" como nas Imagens II e III.

Se considerarmos apenas as teorias administrativas fundamentadas no discurso da organização, da predição e do controle, compreenderemos que não são suficientes ou
Imagem III: Os Gestores, seus desejos e necessidades

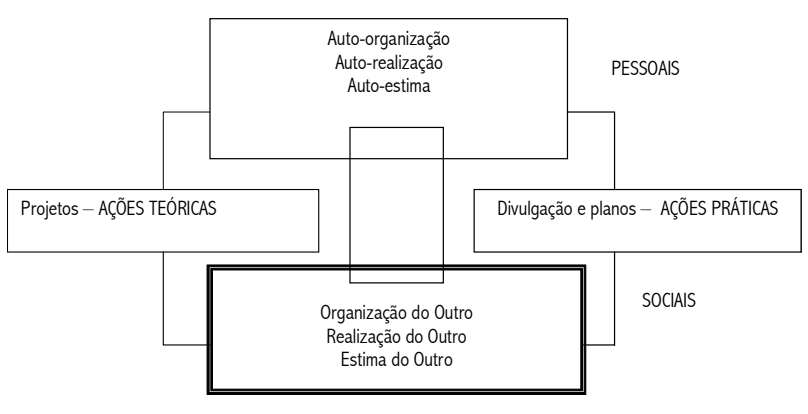

adequadas à dinâmica complexa da biologia gerencial de nosso Programa. Como nos aponta Maturana et al. ${ }^{9}$, o homem/mulher é um ser vivo autopoiético em que o ser e o fazer são inseparáveis, constituindo o seu modo específico de organização que, por sua vez, o define como unidade. A interação das diversas unidadessujeitos envolvidos no Programa, por processos de acoplamentos, geram uma fenomenologia que ainda precisamos compreender.

Em nossos encontros, estamos aprendendo a identificar desejos e necessidades, não como algo idealizado/platônico, mas como o que pode ser testado e visualizado a partir de nós mesmos. Isto já é difícil por si só. Quando voltamos nosso olhar para o outro, temos descoberto que nossos esforços têm sido para nós mesmos, uma vez que instrutores, pais e alunos desejam e têm necessidades diferenciadas. Em muitas dessas necessidades, não podemos sequer intervir, por serem de cunho pessoal ou por estarem em um espaço que não transitamos; em outras, envolvem economia, segurança, emprego, educação e normas de comportamento exclusivas do ambiente familiar e de sua organização como sujeito.

Para nós, se o Programa tem se apresentado como um sistema aberto-orgânico-complexo, é preciso considerar a imensa rede social-ambiental-emocional que existe em seu interior. Nesta rede, uns fios são extremamente fracos e outros extremamente fortes, onde quem é dono do espaço manda e quem precisa dele se assujeita.

Como encontrar, então, um gradiente ideal ao coletivo? Que elo romper sem perder a idéia do coletivo? Não sabemos se fazemos do modo como deve ser feito (será que existe uma fórmula?). Todavia, nossos objetivos têm emergido do processo fundamental de buscar explorar, escutar e entender os valores e necessidades de nossos clientes e parceiros, em especial os que se inserem nas atividades de esporte e lazer. Nem sempre é possível atendê-los, mas temos discutido nossas intenções/ ações com a "alma aberta" em nossos encontros (Imagem IV).

As aberturas criadas no processo de gerenciamento da rede possibilitam reinventar as nossas propostas/ações e rever

$\overline{\text { Imagem IV: Gerenciando a Rede }}$ 
normas/regras operacionais necessárias à nossa autoorganização. Esta auto-organização exige um certo grau de ordem hierárquica dos sujeitos participantes; uma hierarquia que não é estática, imóvel ou engessante. Ela é emergente e flexibilizada, a partir das situações vivenciadas e das contribuições que cada um precisa dar ao Programa, sejam coordenadores, clientes, docentes, discentes ou instrutores.

As inter(rel)ações, que entram e saem, são construídas em nossas reuniões e ações dentro e fora da Universidade. Elas guardam relações-chave entre o ambiente (onde tudo acontece) e o funcionamento das três células, entre as quais temos criado dependências mútuas como modo de mantê-las vivas, tal como um sistema biológico que se auto-regula 0 tempo todo, como capacidade e princípio de conservar o equilíbrio dos sujeitos e das Instituições envolvidas.

Nossa homeostase pertence à dinâmica do desequilíbrioequilíbrio, quando brigamos, discordamos e concordamos dependendo do assunto que se discute, fato, aliás, que consideramos normal porque o sentido de rede está muito presente no grupo. Assim, a lei que nos rege é manter o programa funcionando para atender as necessidades das "células orgânicas".

Em muitas reuniões do grupo gestor ou com a comunidade, a temperatura pode subir como num corpo com febre. Porém, ao mesmo tempo, esse corpo busca transpirar seus próprios desequilíbrios-problemas como um modo de normalizar os processos de controle para a homeostase.

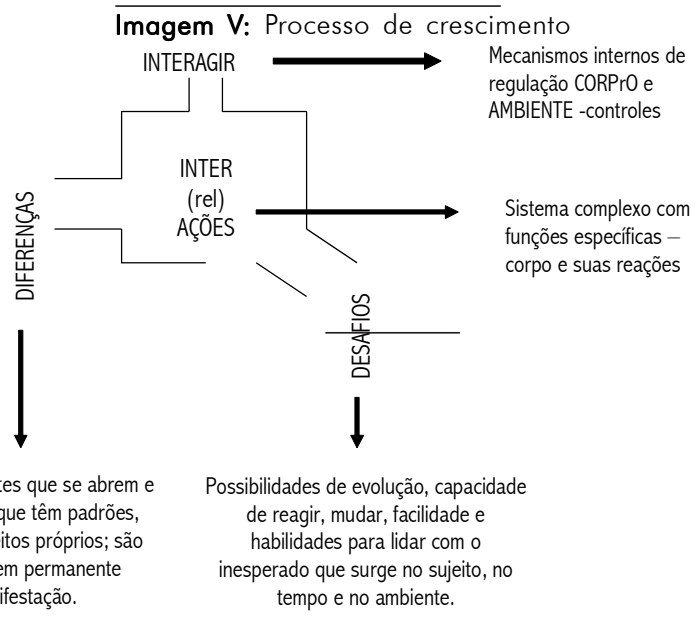

A Imagem V trata do controle do processo. Nela é possível identificar que não estamos preocupados com um sujeito em especial, mas com o conjunto. Este fato tem nos exigido idas e vindas sobre o que queremos e o que entendemos por gestão de um Programa, envolvendo duas Comunidades e uma Universidade com discursos tão variados, às vezes paradoxais.
Finalmente, é necessário dizer que esta é nossa primeira produção, versando sobre a gerência do Programa Fábrica de Cuidados, sobre o trabalho de um grupo que tenta gerenciar sem recursos e sem efetivo poder institucional, se pensarmos no apoio que a Universidade tem oferecido.

Como gestores, nosso cuidado tem sido pensar como moldar nossa prática para um sentido que interesse a todos e que viabilize resultados a partir do que toda comunidade deseja. Por isso, temos tentado sair de "canoas furadas", em que muitas vezes destruímos criativamente o que havíamos proposto ou implantado. Outras vezes, temos que recomeçar sempre, pois "gestão depende, depende, depende de circunstâncias"4.

Se gerenciar o Programa tem sido, para nós, uma forma de fazer ciência, precisamos continuar pensando e modelando esse pensamento para que nos guie ao saber e às práticas na gestão, no ensino e na saúde.

\section{CONSIDERAÇÕES FINAIS}

Neste estudo, buscamos as facilidades e dificuldades existentes no gerenciamento das relações humanas durante a implantação de um Programa Comunitário.

As facilidades destacadas dizem respeito à capacidade de adaptação e sobrevivência às situações adversas e indesejáveis, a partir do estímulo dos gestores e dos clientes participantes do Programa Fábrica de Cuidado.

As dificuldades geradas foram fruto de impossibilidades para atender algumas necessidades da clientela. Essas necessidades se encontravam fora do escopo do Programa, cujo princípio norteador é o conceito de saúde. 0 maior desafio foi conviver com a incompreensão de alguns clientes em participar das atividades de esporte e lazer sem o nosso compromisso de torná-los atletas.

Consideramos que esses 10 anos de experiências na implantação e implementação do Programa Fábrica de Cuidados foram suficientes para a criação de relações seguras e sustentáveis entre docentes e comunidades. Todavia, ainda surgem alguns interesses ou necessidades antagônicos ao Programa. Por isso, cremos que ainda estamos construindo nossas redes e buscando formas de for talecer nossos vínculos pessoais-individuais-socias quando nos encontramos para planejar, atuar ou jantar juntos.

Essas diferentes estratégias de encontros têm aumentado a confiança de uns para com os outros e proporcionado a flexibilização de objetivos/metas para que todos possam ser agraciados. Isso tem nos obrigado a ceder e avançar nos desejos e nas necessidades de cada um, tanto nas questões coletivas como individuais. Ao mesmo tempo, temos aprendido a buscar coletivamente outros caminhos e "fugas" para resolver problemas que envolvem a comunidade, sem perder de vista a idéia de saúde como uma questão fundamental do Programa. 


\section{Referências}

1. Motta RP. Gestão contemporânea: a ciência e a arte de ser gerente. $13^{\mathrm{a}}$ ed. Rio de Janeiro (RJ): Record; 2002.

2. Minayo MCS, Assis SG, Souza ER. Avaliação por triangulação de métodos: abordagem de programas sociais. Rio de Janeiro (RJ): FIOCRUZ; 2005.

3. Morgan G. Imagens da organização. São Paulo (SP): Atlas, 2000.

4. Nóbrega C. A ciência da gestão. $2^{\mathrm{a}}$ ed. Rio de Janeiro (RJ): SENAC; 2004. 5. Foster R, Kaplan S. Destruição criativa. Rio de Janeiro (RJ): Campus; 2002.

6. Taylor F. Princípios científicos de administração. New York (USA): Harper \& Row; 1911.

7. Fayol H. Administração geral. Londres: Pitman; 1949.

8. Maslow AH. A teoria da motivação humana. Psycholog Rev 1943; 50: 370-96.

9. Maturana HR, Varela FJ. Aárvore do conhecimento: as bases biológicas da compreensão humana. São Paulo (SP): Palas Athena; 2001.

\section{Sobre os Autores}

\section{Eva Maria Costa}

Mestre em Enfermagem. Professora Adjunta do DEF / EEAP / UNIRIO.

Nébia Maria Almeida de Figueiredo

Doutora em Enfermagem. Professora Titular do DEF / EEAP / UNIRIO

Eduardo Gusmão

Presidente daAssociação dos Moradores da Vila Benjamin Constant/AMOVILA.

\section{Teresa Tonini}

Doutora em Saúde Coletiva. Professora Adjunta do DEF / EEAP / UNIRIO.

Abilio Tozini

Presidente daAssociação dos Moradores da Lauro Muller eAdjacências / ALMA.

\section{Wilma Ferreira Araújo}

Especialista em Administração Escolar / UNIRIO. 